\title{
Research on Ideological and Political Education of University Students Based on Dormitory Culture Construction
}

\author{
Miao Gao ${ }^{1,}$ a , HongXing Song, ${ }^{2, \text {,* }}$ \\ ${ }^{1}$ College of Chemistry and Biology , Beihua University, Jilin City, Jilin Province, China \\ ${ }^{2}$ Jilin Vocational College of Industry and Technology, Jilin City, Jilin Province, China \\ * Corresponding author
}

Keywords: Dormitory culture, Ideological and political education of university students.

\begin{abstract}
The dormitory culture is an important constituent of campus culture and an important bearer with students' dormitories as place. The dormitory culture can direct the idea of undergraduates to a certain extent, so, to relentlessly explore the new thinking for construction of dormitory culture is an imminent task in construction and development of college dormitories, and also has profound significance in ideological and political education.

In Chinese colleges, the dormitories have become an important place for students to exchange, thereby forming dormitory culture which influences development of undergraduates' idea and psychology while normalizing and leading their behaviors. Therefore, to promote ideological and political education of undergraduates via strengthening construction of college dormitory culture has emerged as a new way for this education work.
\end{abstract}

\section{The problems in current construction of colleges' dormitory culture}

Presently Chinese colleges are all enhancing construction of campus culture through a lot of measures, and construction of dormitory culture in colleges has made some achievements, yet still with some problems, such as placing a high premium on perfecting hardware facilities and ignoring construction of matched software; stressing school's rules and regulations while ignoring education and leading of students; emphasizing entertainment of activities while ignoring cultural connotation and scientific planning of activities, etc.

Prioritizing hardware facilities over software in construction of colleges' dormitory culture. Recent years witnessed gradually perfecting of dormitories construction and significant improvement of hardware facilities in Chinese colleges, and a great many colleges all make much account of daily management of undergraduates, yet deliver unsatisfactory performance in cultivating their self-education capacity, while now the network which is developing quickly attracts attention of most of students, who prefer to linger in dormitories instead of communicating with others. This has a strong impact on the normal human relation among students, and more importantly, influences their learning and life.

The construction of dormitory culture in colleges stresses entertainment effect and lacks leading of idea. Currently, with dormitories as carrier, the colleges all hold a lot of colorful campus culture activities, such as dormitory culture festival, design contest of dormitories label, etc. However, these activities failed to be well-planned, had unclear activity subject and were not dominated by socialist core values. The educational significance of activities is not profound, leaving students just watching the fun. These activities only stop at entertainment level instead of improving students' ideological and moral cultivation. If the dormitories cultural activities have too much entertaining content, the function of moral education is restrained. 


\section{The relation between colleges' dormitory culture and ideological and political education}

Moral education function of construction of colleges' dormitory culture. The dormitory culture can enrich the form and content of moral education in colleges, and guide and help the undergraduates via a specific mode to define objective of the struggle, scientifically plan life to form views of life, employment and talent up to the expectation of the state and society, thereby accepting education from the depth of the mind.

Through rendering of the cultural atmosphere, fostering of campus spirit, and holding of characteristic activities, the concept of values contained in dormitory culture helps undergraduates to endlessly raise ideological and ethical quality via education, enlightenment, criticism and surveillance, etc., also leads undergraduates to consciously identify with the dominant social value system to arouse their historical mission sense of loving the country and reviving China, thereby establishing value pursuit meeting social requirements.

Psychological molding function of construction of colleges' dormitory culture. The colleges' dormitory culture nourishes students like breeze and soft rain by promoting connection and complementation of the major class education and extracurricular activities, and implementing high-grade cultural activities fusing ideological content, contemporaneity and advancement to raise mental health level of undergraduates, relive psychological pressure, keep a good mindset and construct harmonious interpersonal relationship.

Characterized by persistent and profound influence, the colleges' dormitory culture excavates and excites the apparent and potential positive quality of undergraduates, fosters their active affective experience, to make them actively adapt, develop aggressively, forge ahead and become mature adults who consciously serve the society, have social responsibility sense and development potential. The dormitories also provide an important platform for students to exchange ideas, information and emotion. The harmonious dormitory culture cannot only promote harmonious and free development of undergraduates, but also can harmonize the relation among students, enhance exchange between teachers and students, build harmonious and healthy campus ethos and keep campus stable and safe.

Normalization and restraint function of construction of colleges' dormitory culture. With strong mouldability, the contemporary undergraduates are not only active and creative in thought, but also have high political perspicacity, strong receptivity for new ideas, as well as high political zeal. As a population culture, the dormitory culture can educate students to a certain extent to play a vital function in normalizing and restraining their ideas and behaviors.

Amid long-term practice, affective communication, meeting of minds, and mutual influence in dormitories, the undergraduates gradually formed conventional and non-explicitly provided system and criteria representing common benefit and objective of struggle to profoundly influence and restrain the undergraduates' idea and behaviors. On the one hand, the undergraduates are required to build up the awareness of overall situation, prioritize self-interests over collective interests, consciously observe and maintain harmony and stability of dormitories. On the other hand, an active and healthy dormitory culture atmosphere can inject mission sense, belonging sense and identification sense into the undergraduates, who will actively coordinate interpersonal relationship and build a hardworking and positive cultural and ecological environment.

Distinctive education function of construction of colleges' dormitory culture. In current society which is flooded with multiculture, the colleges' dormitory culture is keeping abreast of times. It also has an important function of distinctive education.

Enhance cultural consciousness, develop and expand national features. The dormitory culture should be supplemented with new times requirements and new content to form national sense of belonging and develop and expand excellent Chinese culture, thereby influencing and educating the undergraduates with a strong atmosphere.

Create brand characteristics and enhance actual educational effect. On the one hand, we should build dormitory culture with local color based on regional economic development, set up brand and expand educational benefit. On the other hand, we should extract college characteristics, keep the 
traditional advantages and combine major characteristics of disciplines to pertinently build school's dormitory culture, foster talents and develop via features.

\section{New way for ideological and political education based on construction of dormitory culture}

Conduct mental health education in dormitories to promote accord development of construction of dormitory culture. This is based on highlighting the advantage of dormitories in floor in extracurricular activities education according to the principle of proximity, and mainly innovates undergraduates' mental health educational activities system and consultancy service system, for the purpose of fostering active dormitory atmosphere, propagandizing knowledge of mental health education, effectively conducting universal consultancy and leadership, so as to ultimately enhance undergraduates' thoughts and understanding, normalize their behaviors, improve their environmental adaptation, interpersonal interaction, appeal to friends, team cooperation and own sense of competence, etc. As an education practical activity omnibearingly cultivating undergraduates' psychological quality, it is essentially an important form for front-type mental health education, also a key method to comprehensively follow out CPC's educational policies in the new situation and effectively exert the educating function of dormitory psychological culture.

Educating via subsidizing in dormitories to embody the humanistic care of construction of dormitory culture. This work is closely related to students' physical demands, so integrating it into activities of dormitory culture construction and carrying out various theme events are not only favorable for implementation of subsidizing work in colleges, but also enriches the connotation of dormitory culture, and more, pioneers a new way for the ideological education in colleges.

The measures include building platform for educating via subsidizing in dormitories, and enriching the content of dormitory culture. To be concrete: we should build strongly pertinent activities platform in dormitory communities, hold multi-leveled and manifold dormitory cultural activities, lay stress on mobilizing the poor students to join the overall process of activities from organization to implementation, and encourage them to take an active part in activities of dormitory communities by providing quality expanding platform and capacities tempering posts. We should also make students find out own drawbacks via activities of different types and qualities to propel them to relentlessly enhance synthesizing and learning, improve overall qualities, stimulate them to stress tempering of overall capacities and improve and build their self-enhancement spirit.

Raise the level of construction team of dormitory culture to exhibit the actual effect of education function of dormitory culture. In construction of colleges' dormitory culture, the managerial staff of dormitories play a vital role. To develop this team cannot only raise dormitory management and service level, show the effect from educating via management and service, but also can actively promote construction and development of dormitory culture to expand the form and content of education via culture. Enhancing dormitories management is an important measure as it produces a positive influence on enriching the team of ideological and political education in colleges, and also fully implements the education in the new situation.

Deepen the understanding and enhance organization and leadership. The leaders in colleges should stress the construction of dormitory management team in thought, embody humanistic care, and advocate due respect for the managerial staff of dormitories from all teachers and students in the school. to provide a good environment for managerial staff of dormitories, enhance executive force of policies, and provide indemnification in system, human power, financial resources and material resources for construction of dormitory management team. In theory, we should enhance research on construction of dormitory management team, perfect and innovate relentlessly to promote the construction of management team of dormitory in colleges.

Deepen the understanding and enhance organization and leadership. The leaders in colleges should stress the construction of dormitory management team in thought, embody humanistic care, and advocate due respect for the managerial staff of dormitories from all teachers and students in the school. to provide a good environment for managerial staff of dormitories, enhance executive force of policies, and provide indemnification in system, human power, financial resources and material resources for construction of dormitory management team. In theory, we should enhance 
research on construction of dormitory management team, perfect and innovate relentlessly to promote the construction of management team of dormitory in colleges.

\section{References}

[1] Wang Xiaohong. The Primal Problems and Countermeasures in Higher EducationDevelopment in China [J]. Jiangsu Social Science, 2012(3)

[2] Liu Chengli. Building of Education Via Subsidizing in Colleges Based on Human-oriented Care [J]. Heilongjiang Researches on Higher Education, 2015(10).

[3] Xu Mu. To Explore the Way for Ideological and Political Education of Undergraduates Via School-enterprise Cooperation from the Perspective of Dormitory Culture [J]. Data of Culture and Education, 2016(3)

[4] Guo Zhenrui. A Multi-dimensional Analysis on Ideological and Political Education in Dormitories in the New Situation [J]. Journal of Higher Education, 2016(10)

[5] Zhang Zhigang. Research on Enhancing the Actual Effect of Party Building Work in Colleges' Dormitories [J]. Party Building in Colleges. 2016(4).

[6]Wang Xiaohong. College students' ideological and political education innovation and development.[J]. The theory of monthly.2012(8). 